\title{
DESAFIOS E OPORTUNIDADES NO ENSINO DE ENGENHARIA A DISTÂNCIA NO BRASIL
}

\author{
SALVADOR/BA JUNHO/2018 \\ Genisson Silva Coutinho - IFBA - genisson@ifba.edu.br \\ Vinicius do Rego Dias - UCSAL - vinicius.dias@pro.ucsal.br \\ Aécio Lira - Universidade Federal de Minas Gerais - aecioflira@gmail.com \\ Tipo: Investigação Científica (IC) \\ Natureza: Planejamento de Pesquisa \\ Categoria: Métodos e Tecnologias \\ Setor Educacional: EDUCAÇÃO SUPERIOR
}

\begin{abstract}
RESUMO
A expansão dos cursos de engenharia a distancia no Brasil tem levantado importantes discussões acerca qualidade e aceitação dos alunos egressos destes cursos. Fatores como preconceito, necessidade de mudança de paradigmas por parte de alunos e docentes, capacitação de pessoal de apoio, além do desenvolvimento de novos equipamentos e tecnologias para laboratórios apresentamse como desafios que podem comprometer o sucesso da EAD em engenharia. Neste artigo, exploramos os principais desafios a serem enfrentados pelas IES durante a implantação e manutenção dos cursos de engenharia EAD e, através de perspectiva crítica e holística, discutimos como tais desafios podem ser compreendidos como verdadeiras oportunidades para o avanço da modalidade no país. A metodologia empregada para a realização do artigo baseou-se em uma pesquisa qualitativa de literatura, associada a discussão crítica entre os autores, contrastando a realidade internacional com a realidade local do país. Os resultados indicam que a educação em engenharia a distância tem o potencial de transformar todo o sistema educacional do Brasil, assegurando educação de qualidade e promovendo inclusão social.
\end{abstract}

Palavras-chave: Engenharia; educação a distância; laboratórios; desafios; oportunidades 


\section{INTRODUÇÃO}

A formação de engenheiros é internacionalmente reconhecida como elemento essencial para o progresso e o aumento da competitividade global de uma nação (BesterfieldSacre, Cox, Borrego, Beddoes, \& Zhu, 2014). O Brasil, apesar da expansão do ensino superior como um todo, ainda apresenta patamares de formação de engenheiros em números bem inferiores a países como Rússia, Irã e Japão, entre outros (Andrade, 2017). Apesar da falta de estudos profundos sobre as causas desta situação, fatores como alto índice de evasão, alto custo dos cursos de engenharia, prevalência de cursos presenciais e a pouca flexibilidade de horários destes cursos contribui para o baixo número de engenheiros formados no país (Andrade, 2017).

A expansão dos cursos de engenharia a distancia no Brasil tem um grande potencial para transformar a realidade da engenharia no país. De fato, grande parte dos fatores descritos acima como potenciais limitadores ao crescimento do número de graduandos em engenharia, é minimizada, ou mesmo eliminada, através da educação a distância. Em primeiro lugar, a flexibilidade dos cursos EAD permite que alunos possam estudar sem limitações temporais ou geográficas. Assim, estudantes que trabalham podem conciliar estudo e trabalho. Pessoas que moram em locais distantes das grandes cidades tem acesso aos pólos onde a qualidade do ensino é comparável ao da instituição central. Em segundo lugar, cursos EAD tem um potencial de inclusão social enorme, haja vista que uma grande parcela da população que hoje se encontra alijada da educação em engenharia, por conta dos altos custos dos cursos presenciais, agora poderá beneficiar-se dos menores custos do ensino a distância. Aliado a esses fatores, a extensa rede de unidades e pólos de EAD no país, contribuem para a rápida capilaridade dos cursos de engenharia a distância, o que possibilitará o acesso a educação em engenharia nas mais distantes regiões do país.

O sucesso dos cursos de engenharia a distância no país, entretanto, não está assegurado apenas pelas vantagens intrínsecas da educação a distância, a saber flexibilidade, capilaridade, e baixo custo. Imensos desafios hão de ser enfrentados por todos aqueles que hoje se propoem a implantar e disseminar esta modalidade de educação em engenharia no Brasil. Dentre estes desafios a necessidade de superar certa resistência por parte da sociedade organizada, o desenvolvimento de novas práticas e métodos pedagógicos, a capacitação de pessoal docente, a mudança de paradigma por parte do aluno EAD e o desenvolvimento tecnológico associado ao uso de laboratórios, se mostram essenciais e darão o alicerce necessário à consolidação desta modalidade no país. Neste trabalho, apresentamos uma discussão acerca dos desafios e oportunidades associadas à expansão do ensino de engenharia a distância 
utilizando um modelo que aborda cinco elementos essenciais na educação: sociedade, aluno, agente educacional, processo pedagógico e tecnologia. Na primeira seção que se segue, discutimos os principais desafios atuais e futuros, baseados em uma perspectiva local e internacional. Em seguida, através de uma visão holística do processo educacional, demonstramos como transformar desafios em oportunidades que levarão à consolidação da educação em engenharia a distância, com reflexos no aprimoramento da educação tradicional da engenharia. Especial ênfase será dada a questão do uso de laboratórios em engenharia a distância.

\section{DESAFIOS DA EDUCAÇÃO EM ENGENHARIA A DISTÂNCIA}

Sociedade: É preciso superar preconceitos ainda existentes. Apesar do crescimento e desenvolvimento da educação a distância no Brasil, parte de sociedade brasileira ainda apresenta um certo preconceito quanto à qualidade e eficácia de cursos EAD (Almeida, 2013). Marchisoti \& colegas (Marchisotti, Oliveira, Santos, \& Lukosevicius, 2016) exploraram as diversas fontes de preconceito quanto à EAD no Brasil. Os resultados indicam que alunos, academia, e até mesmo os empregadores ainda resistem aos benefícios dessa modalidade de educação por razões que incluem falta de credibilidade, baixa divulgação, resistência a mudança e corporativismo profissional, entre outras. Ainda não existem estudos específicos para investigar as consequências desse preconceito sobre a aceitação dos cursos de engenharia EAD. Entretanto, contatos preliminares dos autores com membros da comunidade das engenharias revela ainda haver uma certa desconfiança por parte de empresas, entidade profissionais, associações de engenharia, CREA's e alunos em geral. Parte dessa desconfiança deriva de uma falsa percepção acerca da menor qualidade de cursos EAD em relação a cursos presenciais (Abbad, 2007; Almeida, 2013).

\section{Aluno: É preciso focar em metodologias que estimulem a aprendizagem autônoma}

e duradoura. Educação a distância requer uma sensível mudança de paradigma por partes dos estudantes. O aprender tradicional, caracterizado pela passividade no processo ensino-aprendizagem, não mais se sustenta diante da educação a distância (Behar, 2009). Este fato causa um grande conflito inicial devido ao fato de que a grande maioria dos estudantes que hoje busca modalidades EAD ter sido educada, desde o ensino fundamental até o médio, através de práticas pedagógicas centradas no professor e que não estimulam autonomia e pensamento crítico (Freire, 1998). Aliado a este fato, a maior flexibilidade e a necessidade de conciliar trabalho e estudo podem contribuir para uma certa acomodação do aluno diante da necessidade de estudo contínuo e sistemático do EAD. O desafio que aqui se coloca para educadores e provedores de EAD é o desenvovimento de novas práticas pedagógicas que, através de 
metodologia ativas, estimulem o pensamento crítico, a aprendizagem autônoma e duradoura (Behar, 2009), de modo a garantir o desenvolvimento do conhecimento e das habilidades necessárias aos concluintes dos cursos de engenharia.

Agente educacional: É preciso formar profissionais para um novo modelo de educação tranformadora. O sucesso da educação em engenharia a distância está intimamente relacionado à capacitação dos profissionais que hoje atuam como professores, desenvolvedores de conteúdo, ou tutores/facilitadores presenciais. Professores, normalmente acostumados ao modelo tradicional atuando basicamente como transmissores de conhecimento, precisam agora desenvolver um novo de educação em que os alunos estão no centro do processo educacional. Da mesma, desenvolvedores de conteúdo, bem como tutores e facilitadores presenciais precisam se adequar, ou se desenvolver, para garantir ao aluno da educação a distância a qualidade e os meios necessários ao seu aprendizado. Sair de um modelo tradicional em que basicamente se repetem, ipsis litteris, os conteúdos de livros e manuais para um modelo inovador em que conteúdos precisam ser dimensionados de acordo com as necessidades e características dos alunos, é um grande desafio. Tutores e facilitadores presenciais são aqueles que estão na linha de frente no modelo semipresencial e portanto de fundamental importância para a garantia da qualidade dos egressos. São eles que têm a missão de apoiar os alunos no processo de aprendizagem, ora atuando como apontadores de presença, ora acompanhando as praticas, resolvendo provas ou facilitando a interação em sala de aula (Melli \& Barion, 2017). O papel desses tutores nos cursos de engenharia é ainda acrescido das complexidades inerentes à área de estudo e das demandas por atividades laboratoriais que requerem conhecimento técnico associado ao pedagógico. Capacitar tutores e facilitadores com este tipo de conhecimento é extremante desafiador.

\section{Processo pedagógico: Desenvolver currículos que contemplem novas práticas} pedagógicas, novos sistemas de avaliação e garantam formação de qualidade. Segundo Behar (2009), a expansão dos cursos EAD no país requer um repensar acerca dos modelos pedagógicos atualmente existentes. No caso das engenharias, a regulamentação para cursos EAD ainda se encontra em fase de ajustes, com recentes idas e vindas por parte do MEC. Discutem-se diferentes propostas que vão de cursos totalmente à distância aos semipresenciais ou híbridos. Este último modelo tem atraído a atenção de grande parte das instituições de ensino, e conta com a simpatia de entidades e associações de engenharia por propiciarem a realização de aulas práticas presenciais que são essenciais para a formação de um engenheiro. De qualquer modo, a modalidade de curso é apenas um elemento no processo pedagógico. Outros aspectos, organizacionais, metodológicos e tecnológicos ainda precisam de 
pesquisa e reflexão. No atual estágio da EAD no Brasil, podemos argumentar que as questões de natureza organizacional que envolvem por exemplo, a definição de objetivos de aprendizagem, organização social das classes, e variáveis de tempo e espaço (Behar, 2009), encontram-se num estágio maduro de desenvovimento. Por outro lado, no aspecto metodológico e tecnológico é que se encontram os maiores desafios. É importante se ter em mente que enquanto no ensino de engenharia tradicional, o aluno está continuamente e diretamente ligado aos professores e demais colegas, no EAD esse processo é mediado não apenas pela tecnologia, mas também pela presença de outros agentes como tutores e facilitadores. A interação com professores e demais colegas já não se dá do mesmo modo, e portanto a dinâmica da aprendizagem muda completamente. Esta mudança requer novas práticas pedagógicas, ou novos modos de conectar o aluno com os conteúdos e habilidades necessários. Deixa-se um modelo focado no professor e no ensinar, para um modelo onde o aluno e o aprender são protagonistas. Atualmente há um grande movimento favorável ao uso de metodologias ativas na EAD no Brasil. Por outro lado, é preciso contextualizar tais metodologias aos objetos de aprendizagem das engenharias, e investigar como as novas práticas propostas impactam no desempenho dos alunos. Em paralelo, é de fundamental importância desenvolver nos mecanismos de avaliação que garantam a lisura do processo avaliativo, e permitam um processo de avaliação formativa através do qual, mediante constante feedback, os alunos tenham oportunidade para rever, refletir e reaprender continuamente seus conhecimentos e habilidades.

Tecnologia: A questão dos laboratórios de engenharia. $O$ aspecto tecnológico da educação em engenharia a distância pode ser visto sob uma dupla perspectiva: a) Tecnologia de Informação e Comunicação (TIC) e b) Tecnologias inclusivas para laboratórios. Neste artigo não focaremos nas TIC's pelo fato das mesmas serem objeto de muitos estudos nacionais e internacionais e encontrarem-se num estágio bastante avançado emtermos de EAD. Por outro lado, a questão das tecnologias para laboratório se apresentam bastante desafiadoras. Em primeiro lugar, o custo dos atuais equipamentos utilizados em práticas laboratoriais se torna bastante proibitivo quando se pensa numa perspectiva de escala em que cada pólo EAD precisará de um conjunto completo de equipamentos. Torna-se indispensável o desenvolvimento de novos experimentos, de menores custos, capazes de propiciar aos alunos a oportunidade não apenas de conectar a teoria com a prática da engenharia, mas também propiciar o desenvolvimento das habilidades técnicas e comportamentais necessárias. Em segundo lugar, o desenvovimento destes novos experimentos tem que levar em conta limitações de espaço de modo a permitir que, mesmo pequenos pólos possam garantir práticas laboratoriais de qualidade. Em terceiro lugar, é fundamental a incorporação de novas tecnologias como o uso de laboratórios virtuais e remotos onde o aluno pode aprender 
sem ter que se deslocar para o pólo. Finalmente, entendemos que os tradicionais experimentos de laboratório em que os alunos seguem instruções bastante detalhadas, ou verdadeiras receitas de bolo, não estão adequados à realidade da EAD em engenharia. O desafio aqui é como adequar as atividades de laboratório às características de cada modelo pedagógico ora sendo implementado.

\section{OPORTUNIDADES TRANSFORMADORAS}

Dentro de um perspectiva metodológica crítica e transformadora, entendemos ser papel do pesquisador na área de educação em engenharia, atuar de modo a contribuir para o avanço sistemático das práticas e modelos educacionais, sempre com foco nos principios da qualidade, inclusão social e diversidade. Com base nestes princípios, entendemos que a educação em engenharia a distancia tem um potencial de transformar a realidade socio-educacional brasileira, através da inclusão de uma imensa população atualmente alijada do ensino superior. Cabe a nós pesquisadores, discutir formas de assegurar que os desafios ora descritos se transformem em oportunidades tranformadoras que assegurem a melhoria constante da qualidade da educação oferecida a esta população. Sendo assim, passaremos agora a discutir como transformar desafios em oportunidades na área de educação em engenharia.

Quanto ao preconceito que parte da população aparenta manter em relação a cursos EAD, é importante discutir origens e razões de atitudes preconceituosas. Segundo o dicionário Aurélio, preconceito é uma "ideia ou conceito formado antecipadamente e sem fundamento sério ou imparcial", ou ainda, uma "opinião desfavorável que não é baseada em dados objetivos". Portanto, o preconceito normalmente deriva de ausência de fundamento, de dados objetivos, ou desconhecimento. Entendendo que há ainda preconceito acerca dos cursos de engenharia EAD, faz-se necessário que entidades educacionais identifiquem os atores envolvidos, a saber: potenciais alunos, empresas, entidades ligadas à engenharia e CREA's para identificar os porquês desse preconceito. O conhecer destes porquês indicará caminhos para que se possa esclarecer, através de dados concretos, como a EAD é capaz de garantir a formação de profissionais de engenharia dentro dos padrões esperados pela sociedade. E nesse ponto, identificamos mais uma oportunidade, a possibilidade da discussão acerca do que é esse profissional de engenharia que o Brasil precisa. Naturalmente que esta discussão vem sendo desenvovida no âmbito da ABENGE e dos CREA's, mas certamente um envolvimento maior da sociedade como um todo agregaria em muito ao resultado a ser alcançado.

O desenvolvimento de metodologias que estimulem a aprendizagem autonoma e 
duradoura tem reflexos muito além da EAD. De fato, desde longa data se discute a incapacidade da educação tradicional para formar cidadãos críticos e capazes de aprender por conta própria (Freire, 1998). Muito tem sido feito em termos de inovação na área de educação em engenharia, porém a difusão dessas práticas ainda deixa muito a desejar (Borrego, Froyd, \& Hall, 2010). O que se vê hoje no Brasil, com a expansão dos cursos de engenharia EAD, é uma grande oportunidade para que tais metodologias possam ser implementadas e validades através de pesquisas científicas quantitativas e qualitativas. O sucesso destas metodologias seguramente impactará em todo o sistema educacional brasileiro, do ensino fundamental ao superior.

A formação de profissionais para atuar no processo de educação em engenharia EAD envolve o desenvolvimento de metodologias transformativas em educação, pois o objetivo é não apenas agregar conteúdo técnico ou pedagógico a um profissional já formado e geralmente em plena atividade, mas essencialmente transformar, ou mesmo reconceber, crenças, valores e atitudes adquiridas ao longo de anos e dentro de um paradigma tradicional de educação em que o aluno é um mero receptor de um conhecimento externo, para um paradigma dinâmico onde aluno, escola, professores e mediadores estão em constante transformação e crescimento. Este dinamismo gera inúmeras tensões, inexistentes no modelo tradicional. Muito do que se discute hoje em termos de formação de professores passa por essa mudança de paradigmas, e isso requer também uma mudança nos modelos pedagógicos utilizados na formação destes profissionais. O Brasil passa hoje pela expansão quase explosiva de cursos de engenharia EAD, gerando uma demanda por formação e desenvolvimento incomparáveis a qualquer outro momento no país. Tem-se aí a oportunidade de, não apenas avançar no desenvolvimento da educação transformadora de adultos, mas também desenvolver uma expertise nacional na pesquisa e avaliação de programas de desenvolvimento de profissionais da educação superior, com reflexos imediatos na educação presencial.

O mercado EAD tem marcadamente contribuído para a difusão e consolidação de metodologias ativas em educação. Novos educadores e pesquisadores estão sendo atraídos pelos benefícios da aprendizagem ativa, o que seguramente terá impacto não apenas no aumento da qualidade dos cursos EAD, mas também, propiciará a difusão dessas metodologias para outros segmentos da educação no país através de um processo descrito por Rogers (2003) na Teoria da Difusão da Inovação. De acordo com esta teoria, as inovações se propagam através da comunicação, ao longo do tempo, entre participantes de um sistema social. Sendo assim, é de se esperar que com o sucesso dessa metodologias ativas, dentro de algum tempo veremos tais práticas serem adotadas em todo o país. É importante ressaltar o papel consolidador do pesquisador 
educacional na sistemaização e avaliação científica das diversas metodologias que hoje se desenvolvem no país.

Finalmente, considerando a importância das experiências práticas e laboratoriais para a educação em engenharia, entendemos que especial atenção deve ser dada à questão dos equipamentos para laboratórios de engenharia. Dentro desta perspectiva, associamos o conhecimento dos autores na área laboratorial com uma pesquisa bibliográfica sobre recentes avanços na educação laboratorial em nível internacional. Os resultados indicam que o estado da arte atual ainda requer novos desenvolvimentos para fazer frente aos desafios a se enfrentar. Em primeiro lugar, reduzir custos e otimizar equipamentos para a realidade dos pólos enfrenta dificuldades que vão desde a constante flutação cambial no país, o que impede a importação de componentes industriais mais robustos e miniaturizados, à falta de profissionais capacitados com conhecimento técnico e pedagógico para desenvolver os novos equipamentos. A despeito dessa dificuldade, empresas locais da área tem acompanhado de perto a situação e auxiliado inúmeras instituições a conceber soluções de educação de laboratório adaptada às realidades de cada projeto pedagógico.

Os grandes avanços tecnológicos nas área de automação e tecnologia da informação tem garantido a expansão de laboratórios virtuais e remotos. Estes tipos de laboratório são inerentemente adequados para a educação à distância, apesar de não terem sido necessariamente concebidos para este fim. Nas áreas de ciências, em especial física, química e biologia, laboratórios virtuais já são quase que uma realidade constante. de Jong, Linn e Zacharia (2013) apresentaram uma seleção de estudos comparando o desempenho de alunos utilizando laboratórios virtuais e presenciais. Como resultado eles propoem o uso integrado destas duas tecnologias em benefício da maior aprendizagem na área de ciências. Nas engenharias, o uso de laboratórios virtuais também ganha espaço, quase sempre em conjunção com laboratórios físicos (eg. Abdulwahed \& Nagy, 2013). Recentemente dois dos autores deste artigo desenvolveram em parceria com uma das grandes universidades americanas, uma série de oito diferentes laboratórios virtuais que serão utilizados nos cursos de engenharia aeronáutica e astronáutica da universidade. O laboratórios já foram avaliados por professores e assistentes de ensino, demonstrando grande potencial educacional. Os oito virtual labs envolvem tópicos que cobrem medição com strain gages, ensaios de tração, torção, vigas, treliças, vasos de pressão, entre outros. O trabalho será apresentado na prímeira Connected Learning Summit, a se realizar no Massachusetts Institute of Technology, no mês de agosto. Laboratórios remotos também tem apresentado uma grande expansão, especialmente em países da Europa e Estados Unidos (Esche, 2006). Pode-se afirmar que não há dúvidas quanto à eficácia de 
laboratórios remotos como ferramenta educacional. Entretanto, aspecto tecnológicos, operacionais e de custos ainda parecem inibir uma maior difusão aqui no Brasil. Sem sombra de dúvidas, esta dificuldade inicial é uma grande oportunidade para pesquisadores e desenvolvedores do país, não apenas para desenvolver novos laboratórios remotos, mas também para estimular a realização de pesquisas educacionais na área. Como ponto final nesta discussão acerca de tecnologias para laboratório, é preciso ressaltar que a tecnologia em si é apenas um mediador da aprendizagem, e sua eficácia como ferramenta educacional está intimamente ligada à utlização de metodologias pedagógicas próprias e adequadas a cada projeto pedagógico.

\section{CONSIDERAÇÕES FINAIS}

O avanço da educação em engenharia a distância no país é algo inevitável e de grande efeito social, pois possibilita o acesso superior ao uma grande parcela da população que, seja por dificuldades sociais, econômicas, geográficas, ou de trabalho, não possuem oportunidades de obter uma formação na área. Ademais, um maor número de engenheiros formados no país vem a contribuir para o avanço tecnológico da nossa indústria. Todo este efeito, entretanto, não será automático e nem fruto do acaso. É preciso garantir a qualidade dos cursos através de constantes interações entre IES e sociedade, criação de mecanismos rigorosos de avaliação discente, capacitação de docentes e pessoal de apoio, utilização de metodologias inovadores em educação, e contínua adequação das práticas e tecnologias laboratoriais aos projetos pedagógicos em vigor. Pesquisadores e educadores têm um papel primordial neste processo, não apenas como agentes produtores de conhecimento, mas também como transformadores sociais que são. $O$ trabalho ora apresentado visa, contribuir de forma crítica e sistemática, baseada em dados científicos e experiência dos autores, para a identificação de oportunidades e desafios na educação em engenharia a distância de modo a suportar a melhoria contínua do que podemos chamar sistema de educação a distancia do país. Os resultados apresentados indicam que há muito o que ser feito para garantir a qualidade desse sistema, mas as oportunidade identificadas apontam para grandes realizações e benefícios para toda a população.

\section{REFERÊNCIAS}

Abbad, G. da S. (2007). Educação a distância : o estado da arte e o futuro necessário. Revista Do Serviço Público Brasília, 58(3), 351-373.

Abdulwahed, M., \& Nagy, Z. K. (2013). Developing the TriLab, a triple access mode (hands-on, virtual, remote) laboratory, of a process control rig using LabVIEW and Joomla. Computer Applications in Engineering Education, 21(4), 614-626. 
Almeida, N. P. da S. (2013). Preconceito x Crescimento da educação à distância no Brasil: Uma discussão frente à realidade da unb/uab no curso de pedagogia. Monografia, Universidade de Brasília, Brasília.

Andrade, O. (2017). Uma engenharia mais ampla. Revista Pesquisa FAPESP, 95-98. Retrieved from http://revistapesquisa.fapesp.br/2017/03/17/uma-engenharia-mais-ampla/

Behar, P. A. (2009). Modelos pedagógicos em educação a distância. Modelos Pedagógicos em Educação a Distância. Porto Alegre: Artmed.

Besterfield-Sacre, M., Cox, M. F., Borrego, M., Beddoes, K., \& Zhu, J. (2014). Changing engineering education: Views of U.S. faculty, chairs, and deans. Journal of Engineering Education, 103(2), 193-219. https://doi.org/10.1002/jee.20043

Borrego, M., Froyd, J. E., \& Hall, T. S. (2010). Diffusion of Engineering Education Innovations: A Survey of Awareness and Adoption Rates in U.S. Engineering Departments. Journal of Engineering Education, 99(3), 185-207.

Chaquine, L. P., \& Mill, D. (2012). A prática pedagógica na educação a distância e as transformações na docência. In SIED - Simpósio Internacional de EDucação a Distância. EnPED - Encontro de Pesquisadores em Educação a Distância.

de Jong, T., Linn, M. C., \& Zacharia, Z. C. (2013). Physical and virtual laboratories in science and engineering education. Science, 340(April), 305-308.

Esche, S. K. (2006). On the Integration of Remote Experimentation into Undergraduate Laboratories-Technical Implementation. International Journal of Instructional Media, 33(1), 43.

Freire, P. (1998). Pedagogia do Oprimido. Rio de Janeiro: Paz e Terra

Melli, N. C. de A., \& Barion, E. C. N. (2017). A importância da capacitação direcionada a tutores - Uma experiência baseada em um curso técnico de guia de turismo - Modalidae EAD. In 24 CIAED. Foz do Iguaçu: ABED.

Rogers, E. M. (2003). Diffusion of Innovations (5th ed.). New York, NY: Free Press. 